\title{
Health Risk Associated with Near-Road Ambient Air Concentration of Particulate Matter in Mukono Municipal Council, Uganda
}

\author{
Edward Kibikyo Mukooza ${ }^{1 *}$, Sarah Kizza-Nkambwe ${ }^{2}$ \\ ${ }^{1}$ Uganda Christian University, Faculty of Health Sciences, Department of Public Health \\ ${ }^{2}$ Uganda Christian University, Faculty of Engineering and Environment
}

\begin{abstract}
More than $98 \%$ of urban centres exceeding 100,000 people in Low and Middle-Income Countries (LMICs), do not meet the WHO air quality limits. Data on air pollution from LMICs is scarce. We measured the mean concentrations of near-road PM2.5 in the period of Aug.-Dec. 2020, described the Mukono Municipality's near-road populations' exposure to PM2.5, and assessed the associated health risk. PurpleAir PA-II laser particle counters, measured near-road ambient air PM2.5 concentration in Mukono Municipality during the period of 09/1/20 to 12/04/20. Excel Toolpak was used for data analysis and the health risk assessed with the WHO AirQ+ tool. The mean ambient near-road PM2.5 in Mukono Municipality were 30.97, 33.84 and 47.74 ug/m3for background, nearunpaved and near-paved roads, respectively. Mukono Municipality's population was exposed to ambient PM2.5 concentrations higher than the WHO annual limit of $10 \mathrm{ug} / \mathrm{m} 3$. This level of air pollution is associated with preventable annual premature deaths of up to 133.11 per 100,000 population. Vehicles were assumed to be the predominant source of near-road ambient air PM2.5 pollution. The Municipality's population was exposed to near-road ambient air PM2.5 exceeding the WHO annual limit by as much as *4.7 for the paved roads, *3.3 for the unpaved roads and *3 for the background. This leads to increased risk of preventable premature deaths in the Municipality.Mukono Municipality could monitor PM2.5; guide developers to placebuildings more than 100 meters away from roadsides and should promotepolicies for newer vehicles on Ugandan roads.
\end{abstract}

Keywords: Ambient Air quality, Health risk, Mukono Municipality, Near-Road, PM 2.5.

\section{Introduction}

The United Nations categorizes clean air as a human right $[1,2]$. Air pollution is defined by the World Health Organisation [3] as "contamination of the indoor or outdoor environment by any chemical, physical or biological agent that modifies the natural characteristics of the atmosphere". Air Pollution can be ambient (outdoor) or household (indoor) but one can contribute to the other. According to the World Health Organisation, air pollution is the number one environmental health challenge with 7 million premature deaths associated with it and over $90 \%$ of the global population living in areas with air pollutants exceeding the WHO limits [4]. To guide member countries on air quality improvement, the United Nations set targets for air quality in SDGs 3.9, SDG 7 and SDG 11.6 and WHO set air pollution limits $[5,6]$. According to WHO [7], pollutants with strongest evidence of negative health effects are particulate matter (PM), Ozone $\left(\mathrm{O}_{3}\right)$, Nitrogen dioxide $\left(\mathrm{NO}_{2}\right)$ and Sulphur dioxide $\left(\mathrm{SO}_{2}\right)$. Particulate matter PM 2.5 is independently and consistently associated with the most serious health risks, even when the ambient concentration is below the WHO limits $[8,9]$. The World Health Organisation [10] asserts that air pollution is associated with excess Ischemic Heart Disease, Stroke, Chronic Obstructive Pulmonary Disease, Lung Cancer and Acute Respiratory Infections in children. The World Health Organisation estimates that outdoor air pollution leads to 4.2 million pre-mature deaths annually, and of these, 91\% occur in Middle and Low-Income Countries (LMIC) like Uganda. A recent study by Lelieveld and others [11] found that air pollution leads to more premature deaths than previously known, by a factor of two. Air pollution tends to be worse in urban areas and according to WHO, more than $98 \%$ of urban arreas with populations 
exceeding 100,000 population in LMIC, do not meet the WHO limits $[12,13]$. Data on air pollution, especially from LMIC, is limited [12, 14]. Particulate matter, which has no known threshold below which there is no health risk, is used as a proxy indicator for air quality since it is the most health damaging air pollutant $[15$, 16]. Literature shows that at population level, a $6 \%$ increase in all-cause mortality is associated with each $10 \mu \mathrm{g} / \mathrm{m}^{3}$ rise in ambient air particulate matter of size $2.5 \mu \mathrm{m}$ [PM2.5] [5, 15, 16]. The few publications from Uganda show that air in Kampala City and in the surrounding urban centers is polluted with particulate matter concentrations exceeding the WHO guidelines [17, 18, 19, 20]. Roadsides of busy highways are some of the most polluted sites in urban areas due to the presence of dense human and motor traffic [21, 21, 22, 23]. According to the World Health Organisation, PM2.5 originates primarily from combustion sources such as fossil fuel driven automobiles and biomass burning [5]. Limits of $10 \mu \mathrm{g} / \mathrm{m}^{3}$ for annual mean and $25 \mu \mathrm{g} / \mathrm{m}^{3}$ for 24-hour mean of PM2.5 were set by WHO [5] to guide efforts to improve air quality in the varying contexts. There is scarce data on Ugandan urban near-road air qualityand the health risks associated with it is unknown. Using low cost real time laser sensors of the type PurpleAir PA-II, this study measured the mean ambient air concentrations of near-road PM2.5 in Mukono Municipality during the period August $12^{\text {th }}$ to December $4^{\text {th }} 2020$, described the Municipality's near-road populations' exposure to PM2.5 and assessed the associated health risk.

\section{Methodology}

\section{The Setting}

Mukono Municipality with coordinates of $0.3549^{\circ} \mathrm{N}, 32.7520^{\circ} \mathrm{E}$ and an area of approximately $210 \mathrm{sq} \mathrm{km}$, is 21 kilometers from Kampala along the Kampala-Jinja highway which serves the countries of Kenya, Uganda, Rwanda, Burundi, South Sudan and Eastern Democratic Republic of Congo.Mukono district has a mean temperature of about 25 degrees celcius; humidity of about $75 \%$ and wind speed ranging between 4 and 12 kilometers per hour. The area has 5 to $>200$ mmof rain every month with peak rains in April/May and October/November [24]. The Kampala-Jinja
Highway is paved with bitumen, but most roads are gravel. Topography of the Municipality is generally homogeneous with single storey or low-rise buildings located close to either side of the roads (Figure 2). There is limited vegetation along the roads in the Municipality.Most buildings serve a dual purpose of business and accommodation and therefore, there is a high density of people working and residing alongside the roads in Mukono municipality.

\section{Materials}

Seven laser particle counters of the type PurpleAir (PA-II), were used to collect data for the period Aug-Dec 2020. The PA-II sensors' data correlate highly $(r>0.9)$ with the Standard United States Environmental Protection Agency (EPA) methods [25]. The sensors' range of 20 +60 ${ }^{\circ} \mathrm{C}$ and 0 99\% fits with the Mukono environment with high humidity most of the year and temperature of $24-33^{\circ} \mathrm{C}$ [26]. The PAII effective range of $0 \sim 500 \mu \mathrm{g} / \mathrm{m}^{3}$ and maximum range of $\geq 1000 \mu \mathrm{g} / \mathrm{m}^{3}$ is appropriate in environments where previous studies in nearby towns found concentrations of particulate matter above $100 \mu \mathrm{g} / \mathrm{m}^{3}[17,18,27]$. In consideration of the Mukono Municipality land area and population, the EPA urban scale of representativeness and the European Joint Research (JRC) centre recommendations, seven sensors were considered adequate to collect representative data [28, 29]. Each sensor was fixed at a purposefully selected near-the-road location in Mukono Municipality at a height of about 3 to 5 meters above the ground, connected to stable power and $\mathrm{Wi}-\mathrm{Fi}$, away from any obstructions and between 10 and 80 meters from the edge of the road [28].

\section{Data Collection and Analysis}

The PA-II laser particle counters report PM2.5 mass concentration to the purple air map in $\mu \mathrm{g} / \mathrm{m} 3$ on a downloadable excel sheet. The data was downloaded and analysed with Excel data analysis toolpak. The health risk was calculated using the World Health Organisation's AirQ+ - v.2.0 tool for health risk assessment of air pollution [15]. The 24 hour PM2.5 means were compared with the WHO guidelines since Uganda does not have published national ambient air quality standards [30]. The WHO tool calculates health risk for a defined population like that of Mukono 
Municipality [5, 15]. The adverse health outcome of interest in this study was preventable premature deaths due to long-term exposure to air pollution. The World Health Organisation [5] annual mean air quality limits for PM2.5, the ambient air PM2.5 mean measured by PA-II sensor during the data collection period of Aug-Dec. 2020, the Uganda crude death rate of 655.4/100,000 and an estimated population of 162,744 were used in the health risk assessment [5, 31]. The Environmental Health Risk Assessment Model (enHEALTH) [32] informed the methodology. The main issue being the potential gain in terms of premature deaths prevented if the quality of air in Mukono Municipality was maintained within the WHO [5] limits. The main hazard considered in this study was the near-road ambient air PM2.5 concentration. The main exposure pathways were considered being inhalation and contact with eyes and the skin.

\section{Ethical Considerations}

The protocol was submitted to the Uganda Christian University Research Ethics Committee for review and thereafter to the Uganda National Council for Science Technology, which granted permission number HS651ES to conduct this study. At each of the selected sampling sites, permission was obtained from the buildings' owners to permit mounting of the sensors.

\section{Definitions}

\section{Particulate Matter}

Particulate matter is a mixture of solid and/or liquid particles which may be organic or inorganic in nature. Particulate mattercan be $\leq$ PM10, which is equal to or less than ten microns; equal to or less than 2.5 microns (PM2.5) and the ultrafine PM1, which is equal to or less than one micron. Particulate matter size of focus in this study was PM2.5 because, according to the World Health Organisation, long-term exposure to PM2.5 is consistently associated with adverse health issues [8,9].

\section{Near Road}

Distances ranging between 0 and 100 meters from the edge of a selected road. Within this distance, there is a little decay of particulate matter (PM) concentrations related to road activity [36].

\section{Background Air Quality Data}

This is a concentration of PM2.5 due to natural or unidentified sources.

In this study, population in areas more than 100 meters from the roadsides were assumed to be exposed to background air quality measured by the UCU Hamu Sensor.

\section{Health Risk}

The proportion of harmful consequences associated with exposure to PM2.5.

\section{Results}

\section{Mean Near-Road PM 2.5 Ambient Air Concentration in Mukono Municipal Council in the Period August 12th, 2020 to December 4th, 2020}

Figure 1 shows the trend of PM2.5 ambient near-road air concentrations recorded by seven laser sensors during the period $12^{\text {th }}$ August to $4^{\text {th }}$ December 2020 versus the annual WHO limit of ambient air PM2.5 concentration which is $10 \mathrm{ug} / \mathrm{m} 3$ [5]. The sensors' readings were all above the WHO [5] limit exept for UCU HamuMukasa Library and Namilyango Senior Secondary School (SSS) sensors on one day of 16th November 2020. Also, the trendlines for Namilyango SSS and for UCU Tech Park were generally lower than records from other sensors. The sensors with lower tred lines were on a busy but unpaved road used as an alternative route through Mukono Municipality during heavy traffic.

The 24-hour mean near-road ambient air PM2.5 concentrations for five sensors were found to be above the WHO (2005) limit of 10 $\mathrm{ug} / \mathrm{m}^{3}$ for the entire period of data collection. For the sensor at UCU Hamu which worked as the control and the sensor at Namilyango SSS which was alongside an unpaved road, the 24hour mean near-road ambient air PM2.5 concentrations were below the WHO [5] limit of $10 \mathrm{ug} / \mathrm{m} 3$ for one day during the whole period of data collection. When a hypothetical Mukono Municipality limit of $31 \mathrm{ug} / \mathrm{m}^{3}$ was assumed, the exceedences were still high, ranging from $35 \%$ at the background sensor to 99\% at Church of Uganda Hospital's sensor (Figure 2).

The sensors at the Church of Uganda Hospital, St. Paul Wantone and at Seeta Highway recorded the highest mean 
concentrations of ambient near the road PM2.5 concentrations and they also had higher standard deviations [Table 1].The mean nearroad ambient PM2.5 concentrations were lower for the unpaved roads compared to the paved roads. A t-test was performed to compare the 24-hour means for near-road ambient PM2.5 concentrations alongside the paved versus those of the unpaved roads and the difference was found to be statistically significant with a pvalue of 0.001 . The 24 hour mean near-road ambient PM2.5 concentration for the UCU Hamu sensor which provided background data was above the WHO limit of $10 \mathrm{ug} / \mathrm{m} 3$ for $99 \%$ of the days during data collection.

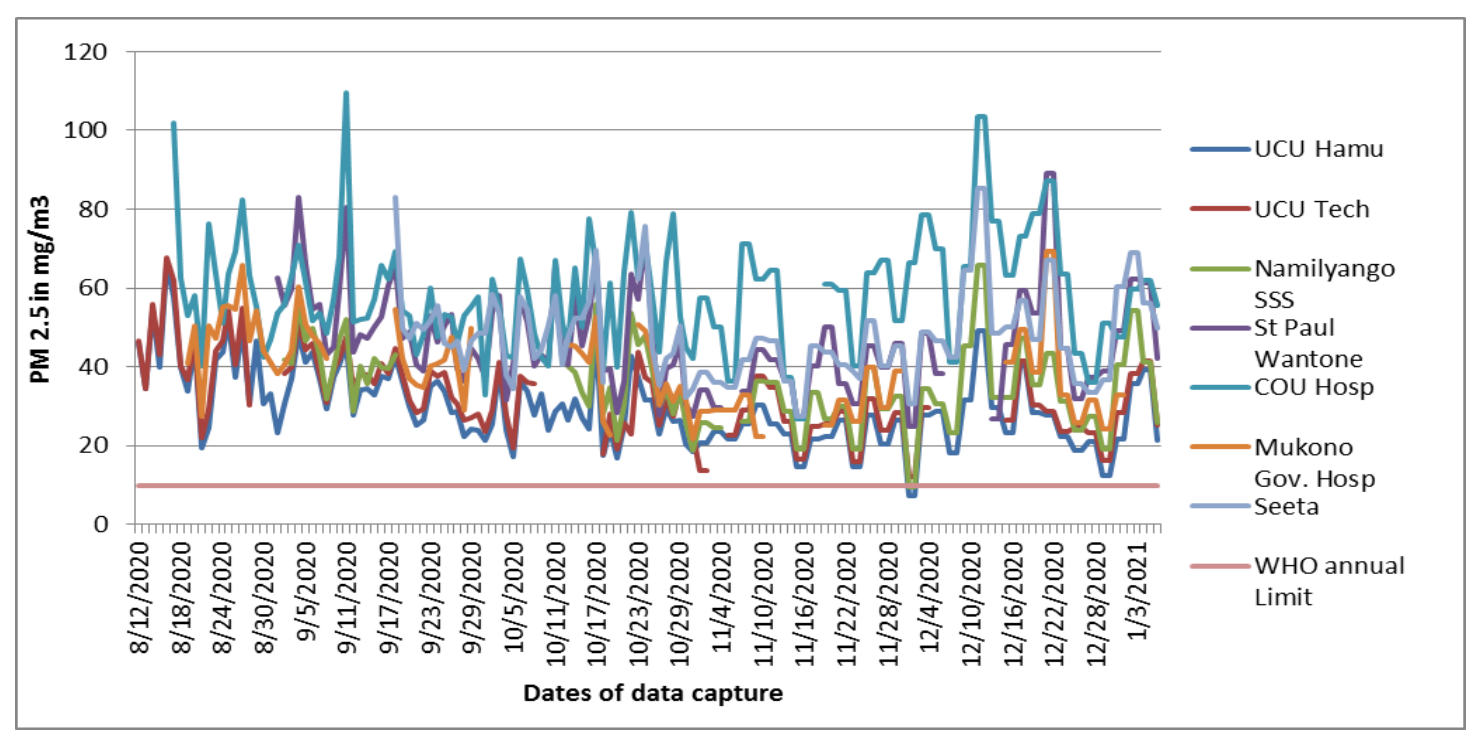

Figure 1. The Trends of Mean Concentration of PM 2.5 Recorded by Seven Sensors across the Period $12^{\text {th }}$ August to $4^{\text {rd }}$ December 2020 in Mukono Municipality, Uganda

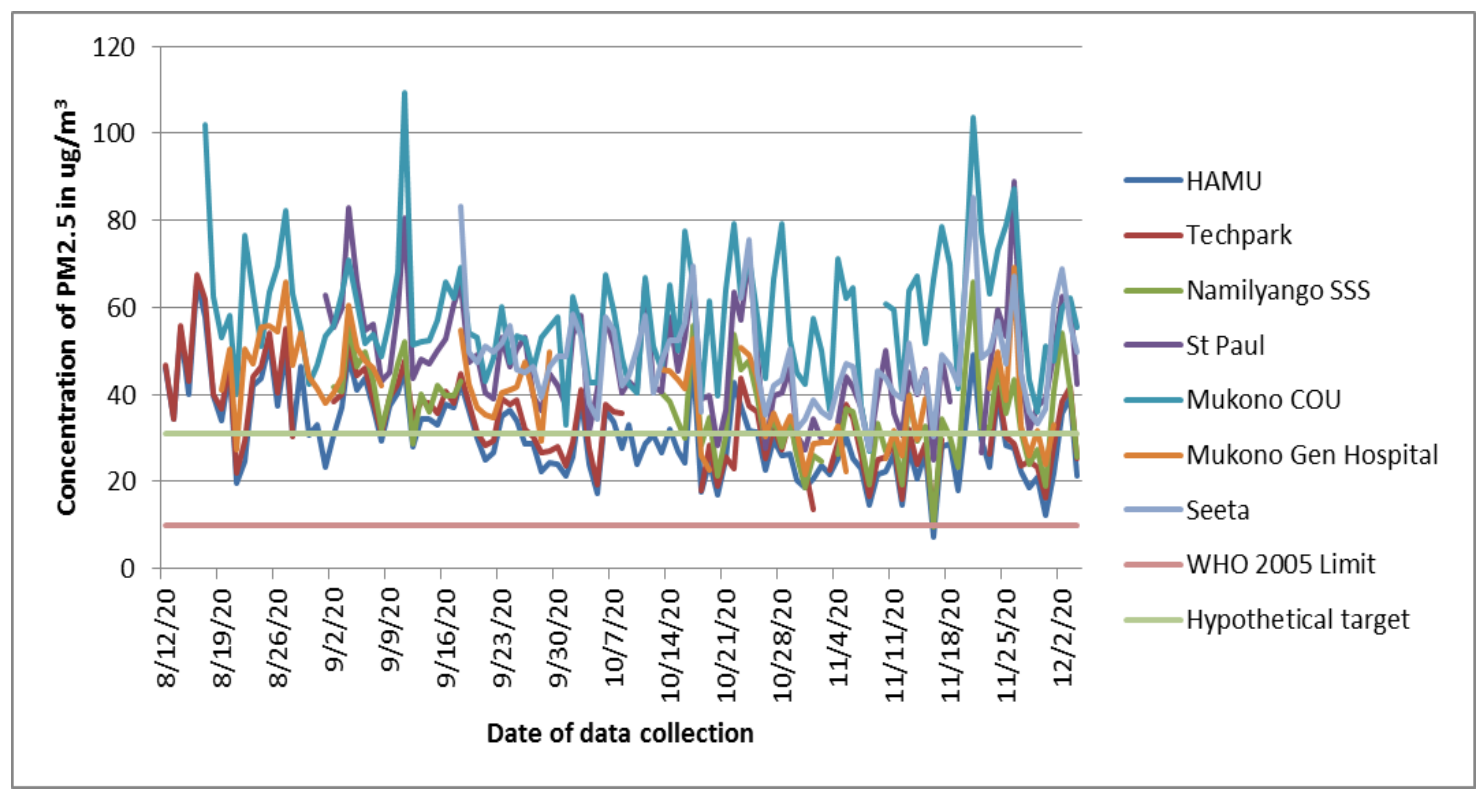

Figure 2. Means exceeding a hypothetical Mukono Municipality target of $31 \mathbf{u g} / \mathbf{m}^{3}$ 
Table 1. Descriptive Statistics of Mean, Minimum, Maximum, Standard Deviation, Percentage of days Exceeding WHO Limit of $10 \mathrm{ug} / \mathrm{m} 3$ and Percentage of Days Exceeding a Hypothetical Mukono Municipality limit of $31 \mathrm{ug} / \mathrm{m} 3$ for Seven Sensors

\begin{tabular}{|c|c|c|c|c|c|c|c|}
\hline & \multirow[t]{2}{*}{ Sensors } & \multicolumn{6}{|c|}{ Statistic } \\
\hline & & Mean & Minimum & Maximum & SD & $\begin{array}{l}\text { Percentage } \\
\text { of days } \\
\text { exceeding } \\
\text { WHO } \\
\text { limit of } 10 \\
\text { ug/m³ }\end{array}$ & $\begin{array}{l}\text { Percentage of } \\
\text { days exceeding } \\
\text { a hypothetical } \\
\text { Mukono } \\
\text { Municipality } \\
\text { limit of } 31 \mathrm{ug} / \mathbf{m}^{3}\end{array}$ \\
\hline & $\begin{array}{l}\text { UCU } \\
\text { Hamu(Background) }\end{array}$ & 30.97 & 7.25 & 66.25 & 10.12 & 99 & 35 \\
\hline \multirow[t]{3}{*}{ Unpaved } & UCU Tech & 32.17 & 12.13 & 67.62 & 10.21 & 100 & 55 \\
\hline & Namilyango SSS & 35.51 & 9.62 & 65.82 & 10.4 & 99 & 76 \\
\hline & $\begin{array}{l}\text { Mean PM } 2.5 \text { at } \\
\text { unpaved road }\end{array}$ & \multicolumn{4}{|l|}{33.84} & & \\
\hline \multirow[t]{5}{*}{ Paved road } & St Paul Wantone & 46.15 & 25.01 & 85.01 & 12.85 & 100 & 91 \\
\hline & COU Hospital & 58.31 & 26.83 & 109.45 & 14.24 & 100 & 99 \\
\hline & Mukono Gov. Hosp & 38.81 & 21.75 & 69.18 & 10.85 & 100 & 84 \\
\hline & Seeta Highway & 47.67 & 27.29 & 85.22 & 11.56 & 100 & 98 \\
\hline & $\begin{array}{l}\text { Mean PM } 2.5 \text { at } \\
\text { paved road }\end{array}$ & \multicolumn{4}{|l|}{47.74} & & \\
\hline
\end{tabular}

Mukono Municipality's Near-Road Populations' Exposure to PM2.5

A large proportion of the houses which serve as both commercial and residential spaces are located adjacent to the roads in Mukono Municipality as depicted in figure 3.This study focused on ambient air pollution but it was assumed that roadside air also infiltrated into working and residential spaces. The Mukono Municipality populations livingresiding more than 100 meters away from roadsides, which was assumed to be the background areas, were exposed to ambient mean PM 2.5 concentration of $30.97 \mathrm{ug} / \mathrm{m}^{3}$. The population residing within 100 meters of busy unpaved roads were exposed to ambient mean PM2.5 concentration of $33.84 \mathrm{ug} / \mathrm{m}^{3}$. The Mukono Municipality population, located within 100 meters of the paved Kampala-Jinja road highway, was exposed to ambient mean PM 2.5 concentration of $47.74 \mathrm{ug} / \mathrm{m}^{3}$. For the whole of Mukono Municipality population, regardless of location of the residences or workplaces, exceedences of the WHO (2005) limit for ambient air mean PM2.5 concentration in this study was $\geq 99 \%$.

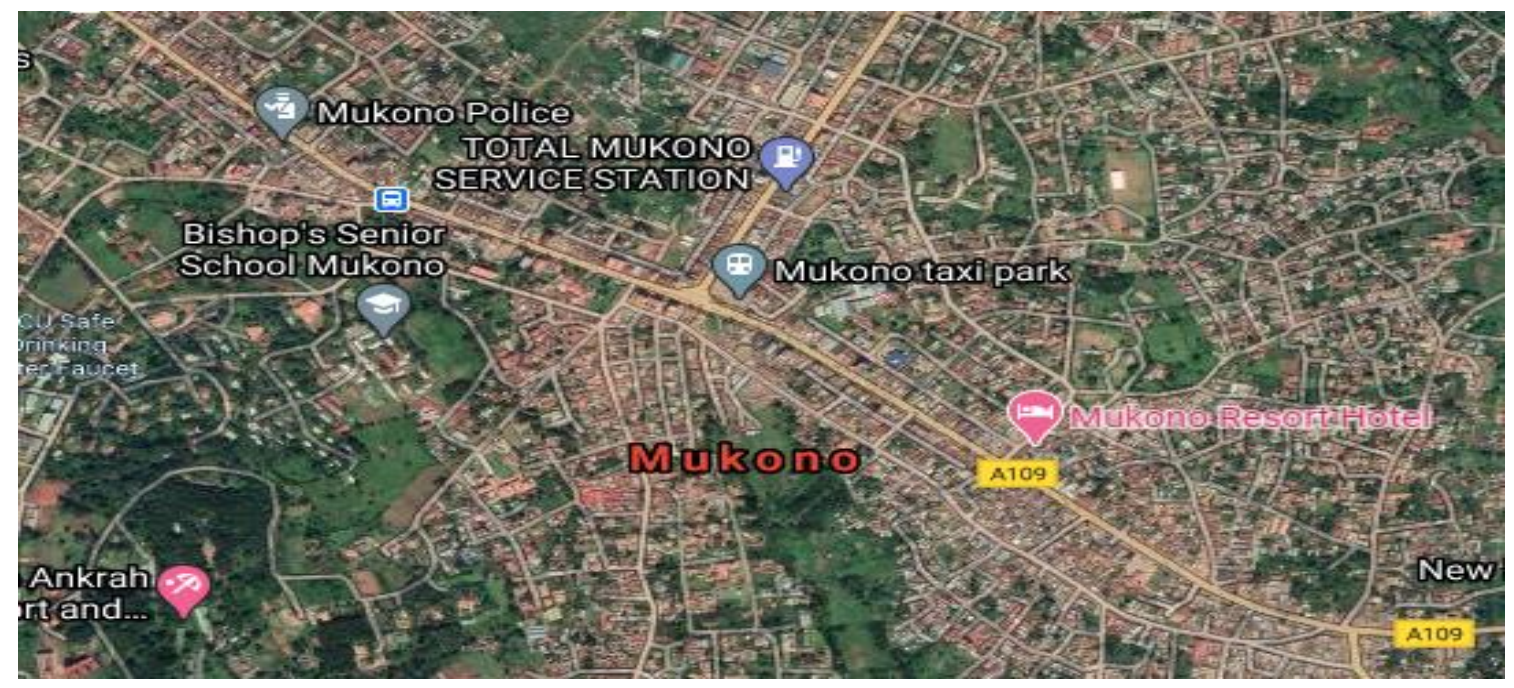

Figure 3. Showing Location of Buildings Adjacent to Roadsides in Mukono Municipality 
A hypothetical Mukono Municipality target of $31 \mathrm{ug} / \mathrm{m}^{3}$, which was measured by the UCU Hamu sensor, was assumed. The sensor collecting background data (UCU Hamu) exceeded the targed for about $50 \%$ of the days of data collection. The sensors on unpaved roads (UCU Techpark and Namilyango SSS), exceeded the hypothetical target for about $70 \%$ of the days of data collection. The sensors on the paved Kampala-Jinja Highway (Mukono COU, Mukono Govt Hospt, Seeta and St PaulWantone), exceeded the hypothetical target for approximately $94 \%$ of the days of data collection.

Table 2. Health Risk Associated with Background Ambient Air Concentration of PM 2.5 in Mukono Municipality

\begin{tabular}{|l|l|l|l|}
\hline & Central & Lower & Upper \\
\hline Estimated Attributable Proportion & $11.34 \%$ & $7.54 \%$ & $14.74 \%$ \\
\hline Astimated number of attributable cases & 121 & 80 & 157 \\
\hline $\begin{array}{l}\text { Estimated number of Attributable } \\
\text { Cases per 100,000 population at risk }\end{array}$ & 74.29 & 49.45 & 96.61 \\
\hline
\end{tabular}

Exposure of the Mukono Municipality population to the ambient background PM2.5 concentration of $30.97 \mathrm{ug} / \mathrm{m}^{3}$ in the long term would lead to more than 121 premature deaths caused by long-term exposure to PM2.5. These deathscould be avoided if concentration of PM2.5 would not exceed $10 \mu \mathrm{g} / \mathrm{m} 3$, which is the threshold recommendation by the WHO Air Quality Guidelines [5].

Table 3. Health Risk Associated with Near-Road Ambient Air Concentration of PM 2.5 along the Unpaved Roads

\begin{tabular}{|l|l|l|l|}
\hline & Central & Lower & Upper \\
\hline Estimated Attributable Proportion & $13.36 \%$ & $8.93 \%$ & $17.31 \%$ \\
\hline Astimated number of attributable cases & 142 & 95 & 185 \\
\hline $\begin{array}{l}\text { Estimated number of Attributable } \\
\text { Cases per 100,000 population at risk }\end{array}$ & 87.56 & 87.56 & 113.46 \\
\hline
\end{tabular}

Exposure of the Mukono Municipality population to the ambient near un-paved PM2.5 concentration of $33.84 \mathrm{ug} / \mathrm{m}^{3}$ in the long term would lead to more than 142 premature deaths caused by long-term exposure to PM2.5. These deaths could be avoided if concentration of PM2.5 would not exceed $10 \mu \mathrm{g} / \mathrm{m} 3$, which is the threshold recommendation by the WHO Air Quality Guidelines [5].

Table 4. Health Risk Associated with Near-Road Ambient Air Concentration of PM 2.5 along the Paved Kampala Jinja Highway

\begin{tabular}{|l|l|l|l|}
\hline & Central & Lower & Upper \\
\hline Estimated Attributable Proportion & $20.31 \%$ & $13.76 \%$ & $25.99 \%$ \\
\hline Astimated number of attributable cases & 217 & 147 & 277 \\
\hline $\begin{array}{l}\text { Estimated number of Attributable Cases } \\
\text { per 100,000 population at risk }\end{array}$ & 133.11 & 90.17 & 170.31 \\
\hline
\end{tabular}

Exposure of the Mukono Municipality population to the ambient near paved road PM2.5 concentration of $47.74 \mathrm{ug} / \mathrm{m}^{3}$ in the long term would lead to more than 217 premature deaths caused by long term exposure to PM2.5. These deaths could be avoided if concentration of PM2.5 would not exceed $10 \mu \mathrm{g} / \mathrm{m} 3$, which is the threshold recommendation by the WHO Air Quality Guidelines [5].

\section{Discussion}

\section{Mean Near-Road PM 2.5 Ambient Air Concentration in Mukono Municipal Council in the Period August 12th, 2020 to December 4th, 2020}

The trends of PM2.5 concentrations in ambient air along near unpaved and near paved roads in Mukono Municipality which was 
recorded by seven Purpleair sensors during the period August $12^{\text {th }} 2020$ to December $4^{\text {th }} 2020$ show air pollution level above the WHO [5] annual limit. This is true even for the sensor which measured ambient background PM2.5 concentration at UCU Hamu.The ambient air concentrations exceeded the WHO [5] annual limit by as much as $* 4.7$ for the paved roads, $* 3.3$ for the unpaved roads and *3 for the background. The PM2.5 ambient air concentration in Mukono Municipal Council was found to be much higher along the busy Kampala-Jinja paved road when compared to the unpaved road $(\mathrm{p}<0.001)$. This was different from the expected and also different from some documented literature [17]. However, the difference may be partly explained by the much heavier traffic on Kampala-Jinja highway when compared to the unpaved roads. The KampalaJinja highway is paved in most places, wider and is preferred by most motorists, especially those driving the large Cargo trucks. Additionally, the Kampala-Jinja highway has dust coming from the multiple potholes which are in the Mukono area. The PM2.5 in ambient air in urban areas is known to be related to fossil powered vehicles' trafficand indeed thebusier traffic locations including Seeta, St Paul Wantone and COU Mukono which recorded the highest PM2.5 concentrations [5, 34]. The heavier traffic which produces a lot of exhaust fumes and non-exhaust dust particles may explain the higher levels of pollution on the paved Kampala-Jinja road versus unpaved roads in the municipality [35]. The sensors at the COU and at the Mukono Government hospitals suggest that the patients and health workers, and especially the inpatients who sometimes stay for many days, may be exposed to high levels of air pollution which may worsen their health complications [36]. A positive correlation between outdoor and indoor PM2.5 has been documented by other researchers and therefore high levels of PM 2.5 does suggest high levels of the same indoors of hospitals, especially where there is no air conditioning as the case is in most Ugandan hospitals [37]. Although there was no accurate record of what proportion of the population in Mukono Municipality live or work within 100 meters of the roads, the google map in figure 3 shows that most houses are located close to the roads and especially close to Kampala-Jinja highway (A109). The 24 hour means of 33.84 $\mathrm{ug} / \mathrm{m} 3$ for the unpaved roads, $47.74 \mathrm{ug} / \mathrm{m} 3$ for the paved roads and $30.97 \mathrm{ug} / \mathrm{m}^{3}$ for the background are all above the WHO [5] 24-hour mean limit of $25 \mathrm{ug} / \mathrm{m}^{3}$ and much higher than the WHO [5] annual limit of $10 \mathrm{ug} / \mathrm{m} 3$ for PM2.5. The mean near-road ambient air concentrations found in this study were similar to the ambient air mean concetrations provided by Airqo station at Mukono Municipality, Ggulu station, which gave a mean of 49.32 (35.6-55.4) in the period of October-November 2020 [20]. The larger standard deviations readings along the paved Kampala-Jinja highway show more variation of ambient PM2.5 concentration probably related to variations in traffic volume, and it also implies that the concentrations frequently rise up to higher levels of health concern. The percentageof days exceeding WHO limit of 10 $\mathrm{ug} / \mathrm{m}^{3}$ for all sensers were high at $\geq 99 \%$ which means that exposure to concentrations of PM2.5 above the WHO [5] limit is long term and therefore, the Munkono Municipality nearthe-road population is vulnerable to the associated health risks of respiratory and heart disease as well as excessive premature mortality [36]. Even if Mukono Municipality targeted a limit of $31 \mathrm{ug} / \mathrm{m}^{3}$, there would still be many days exceeding this limit. This level of air pollution with PM2.5, according to the APA Air Quality Index, is graded as fair to poor and is associated with increased health risks particulay to the populations with pre-existing lung and heart problems. There is no known threshold below which ambient air particulate matter concentration is safe and so any concentrations above the WHO limitsis unhealthy $[5,15,16]$.

\section{Mukono Municipality's Near-Road Populations' Exposure to PM2.5}

Buildings in Mukono Municiplality are located very close to the edge of the road (Figure 2) and this exposes the occupants who work or reside there to high concentrations of PM 2.5 which infiltrates indoors as it disperses $[38,33]$. Some of the buildings are just a few meters off the edge of the road and threfore, close proximity to the road, combined with wind speeds of $4-12 \mathrm{~km} / \mathrm{hr}$ (up to 3 on the Beaufort scale) in Mukono Municipality, results into high concentrations of PM2.5 near the 
roads and thus exposing the population to the associated health risks for long periods of time $[38,24,39]$. The traffic along Kampala-Jinja road is usually very slow because of potholes and congestion, as well as frequent stop-and-go movements. There is a large number of heavyduty cargo trucks on the Kampala-Jinja highway. These trucks are rarely diverted to the smaller unpaved roads. Diesel powered heavyduty trucks are known to be more polluting with PM2.5 and other pollutants than smaller patrol powered cars [38]. These traffic and road characteristics, combined with low wind speed in Mukono, make exposure to PM2.5 air pollution worse [38].

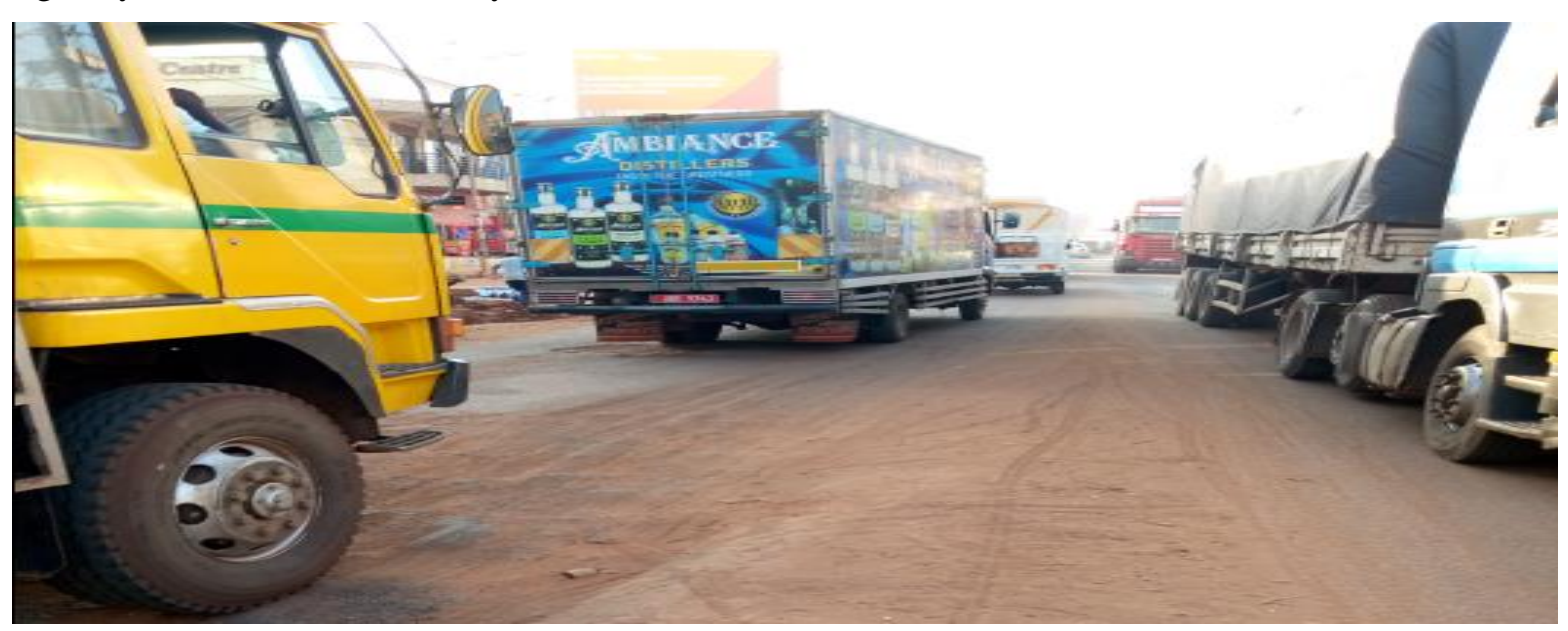

Figure 4. Traffic on Kampala-Jinja Highway near COU Hosp. Showing Lines of Vehicles, Potholes in the Road and a Haze due to Dust and Exhaust Fumes

The population located away from the roads, in the background areas, are also exposed to high levels of PM2.5 with $99 \%$ of the data collection days exceeding the WHO [5] limits. This implies that the whole population in Mukono Municipality, including that living away from the roadsides, is exposed to PM2.5 polution and the associated health risks. However, the risk to ambient PM2.5 exposure is higher for the population living in close proximity of $\leq 100$ meters from the edge of the paved Kampala-Jinja highway which registered the highest ambient mean PM2.5 concentration of $47.74 \mathrm{ug} / \mathrm{m}^{3}$ for the data collection period of August $12^{\text {th }}$ to December $4^{\text {th }} 2020$.

\section{Health Risk Associated with Ambient Near-Road PM2.5 in Mukono Municipality}

The outcome of interest for this near-road ambient air quality study in Mukono Municipality, was the preventable premature deaths if the quality of air met the WHO [5] annual limits or if management of the Municipality set and worked towards a PM2.5 target of $31 \mathrm{ug} / \mathrm{m} 3$ which was found in the background ambient air.The avoidable attributable cases were highest at
$133.11 / 100,000$ population at risk if the whole municipality was exposed to the ambient PM2.5 air quality along the paved roads (Table 4). Along the unpaved roads with ambient PM2.5 mean concentration of $33.84 \mathrm{ug} / \mathrm{m} 3$, the avoidable attributable cases were 87.56/100,000 population if the Municipality's population was exposed to this level of air quality (Table 3). On the other hand, if the Municipality's population was exposed to the background air quality, then the avoidable attributable cases would be 74.29/100,000 population (Table 2). A concentration-response relationship is known to exist between the ambient PM2.5 concentration and morbidity and mortality and the findings in this study are consistent with this literature [5, 40] If the Mukono Municipality leadership were to set a target of $31 \mathrm{ug} / \mathrm{m}^{3}$ for ambient air quality, the WHO AirQ+ (2019) tool shows that the avoidable attributable cases would be fewer at $62.78 / 100,000$ for the paved and $10.92 / 100,000$.for the unpaved roads. This implies that the preventable premature deaths are fewer if the target is set at a higher level, but quickly moving from high levels of air quality pollution to the WHO limit, may not always be possible given what it takes, 
especially considering resource and organizational capacity constraints [5].

\section{Conclusion}

The mean ambient near-road PM2.5 in Mukono Municipalityacross the period AugDec 2020 were $30.97 \mathrm{ug} / \mathrm{m}^{3}, 33.84 \mathrm{ug} / \mathrm{m}^{3}$ and , $47.74 \mathrm{ug} / \mathrm{m}^{3}$ for background, near-unpaved and near-paved roads respectively. These concentrations exceed the WHO [5] limit of $10 \mathrm{ug} / \mathrm{m}^{3}$ for annual ambient air mean. The nature of the roads, the type and charactristics of traffic and the proximity of the business and residential buildings as well as institutions like hospitals to the roads, are the factors which increase exposure of the Municipality's population to high levels of PM2.5. The whole Mukono municipality population is exposed to these high ambient PM2.5 concentrations since even the background mean of $30.97 \mathrm{ug} / \mathrm{m}^{3}$ is much higher than the WHO [5] annual limit of $10 \mathrm{ug} / \mathrm{m}^{3}$. This level of near-the-road, air pollution is associated with up to $133.11 / 100,000$ preventable deaths if the air quality was kept within the WHO [5] limit.

\section{Recommendations}

The Mukono Municipal Council's leadership should be aware of the high levels of air pollution in the municipality and the health risk associated with it. With the current availability of low-cost laser air quality sensors like Purpleair II, which correlate highly ( $r>0.9)$ with the Standard United States Environmental

\section{References}

[1] UN Climate Change. 2019. Clean Air is a Human Right - UN Special Rapporteur. From: https://unfccc.int/news/clean-air-is-a-human-right-

un-special-rapporteur (accessed on the 20th November, 2019).

[2] Boyd D. R. 2019. The Human Right to Breathe Clean Air.Annals of global health, 85(1), 146.https://doi.org/10.5334/aogh.2646.

[3] WHO.2020. Air Pollution. From: https://www.afro.who.int/health-topics/air-

pollution\#: :text=the $\% 20$ human $\% 20$ environment, $\mathrm{O}$ verview,common $\% 20$ sources\%20of\%20air\%20poll ution. (accessed on the $10^{\text {th }}$ of February, 2021).

[4] WHO. 2016a. Ambient air pollution: A global assessment of exposure and burden of disease.From: https://www.who.int/publications-detail/ambient-air-
Protection Agency (EPA) methods, the Municipality can monitor the PM2.5 in real time so that their decisions are evidence based. The Municipallity's planners should guide developers to put residential houses and institutions like hospitals and schools more than 100 meters away from busy roadways [41]. The Municipality's leadership can collaborate with National Environmental Management Authority (NEMA) and the Ministry of Works and Transport to develop policies which promote the use of newer vehicles whose exhaust gases are cleaner for common pollutants, including particulate matter [42].

\section{Limitations}

There were only seven sensors in an area of 210 square kilometers, and data was collected over a period of three months only. There were data collection gaps due to power and or internet disruptions. A longer period of data collection with more sensors would enable comparison of data across seasons.

\section{Suggestions for Further Research}

Indoor air pollution due to infiltration of ambient air PM 2.5 into buildings is likely to be a public health problem, particularly for buildings adjacent to busy motorways. A study to assess Mukono Municipality's indoor air quality would give policy makers more information about the magnitude of the problem.

pollution-a-global-assessment-of-exposure-andburden-of-disease (accessed on the 20th of Nov. 2019).

[5] WHO.2005.WHO Air quality guidelines for particulate matter, ozone, nitrogen dioxide and sulfur dioxide Global update 2005. From: https://apps.who.int/iris/bitstream/handle/10665/694 77/WHO_SDE_PHE_OEH_06.02_eng.pdf;jsessioni $\mathrm{d}=$ FFC62B0AC57ED51601FCB0B92DC728A9?seq uence $=1$.

[6] Institute for Global Environmental Strategies (IGES). 2016. Application of SDGs to Air Pollution. From: https://iges.or.jp/en/pub/application-sdgs-airpollution (accessed on the 5th Dec. 2019).

[7] WHO. 2019a. Ambient air pollution: Pollutants. From: 
https://www.who.int/airpollution/ambient/pollutants/ en/ (accessed on the $20^{\text {th }}$ of Nov. 2019).

[8] WHO. 2013. Health Effects f Particulate matter. From:

https://www.euro.who.int/_data/assets/pdf_file/000 6/189051/Health-effects-of-particulate-matter-finalEng.pdf (accessed on 10th November 2020).

[9] Yu W, Guo Y, Shi L and Li S. 2020. The association between long-term exposure to low-level PM2.5 and mortality in the state of Queensland, Australia: A modelling study with the difference-indifferences approach. Published: June 18, 2020 https://doi.org/10.1371/journal.pmed.1003141 From: https://journals.plos.org/plosmedicine/article/metrics ?id=10.1371/journal.pmed.1003141\#citedHeader.

[10]WHO. 2014. 7 million premature deaths annually linked to air pollution. From: https://www.who.int/mediacentre/news/releases/201

4/air-pollution/en/ (accessed on the $10^{\text {th }}$ December 2020).

[11]Lelieveld J, Pozzer A, Pöschl U, Fnais M, Haines A, Münzel T. 2020. Loss of life expectancy from air pollution compared to other risk factors: a worldwide perspective, Cardiovascular Research, https://doi.org/10.1093/cvr/cvaa025.

[12] WHO.2016c. Air pollution levels rising in many of the world's poorest cities. From: https://www.who.int/en/news-room/detail/12-052016-air-pollution-levels-rising-in-many-of-theworld-s-poorest-cities (accessed on the 23rd of November 2019).

[13] Strosnider H, Kennedy C, Monti M, Yip F. Rural and Urban Differences in Air Quality, 20082012, and Community Drinking Water Quality, 2010-2015 — United States. MMWR SurveillSumm 2017;66(No.SS-13):1-10.DOI: http://dx.doi.org/10.15585/mmwr.ss6613alexternalic on.

[14]WHO.2019b. Air Pollution. From: https://www.afro.who.int/health-topics/air-pollution (accessed on the 1st December, 2019).

[15]WHO. 2018. Ambient Air Pollution (out door).

Key Facts. From: https://www.who.int/newsroom/fact-sheets/detail/ambient-(outdoor)-airquality-and-health (accessed on $6^{\text {th }}$ Jan. 2020).

[16] Sanyal, S., Rochereau, T., Maesano, C. N., Com-Ruelle, L., \&Annesi-Maesano, I. 2018. LongTerm Effect of Outdoor Air Pollution on Mortality and Morbidity: A 12-Year Follow-Up Study for Metropolitan France. International journal of environmental research and public health, 15(11), 2487. https://doi.org/10.3390/ijerph15112487.
[17] Kirenga, B. J., Meng, Q., van Gemert, F., Aanyu-Tukamuhebwa, H., Chavannes, N., Katamba, A., Mohsenin, V. (2015). The State of Ambient Air Quality in Two Ugandan Cities: A Pilot CrossSectional Spatial Assessment. International Journal of Environmental Research and Public Health, 12(7), 8075-8091. https://doi.org/10.3390/ijerph120708075.

[18]Schwander, S., Okello, C., Freers, J., Chow, J.C., Watson, J.G., Corry, M., \&Meng, Q. (2014). Ambient Particulate Matter Air Pollution in Mpererwe District, Kampala, Uganda: A Pilot Study. Journal of environmental and public health.

[19] AirVisual. 2019. World most polluted cities 2018 (PM2.5). From: https://www.airvisual.com/world-most-pollutedcities?continent=59af92713e70001c1bd78e4e\&coun try $=\&$ state $=\&$ page $=1 \&$ perPage $=50 \&$ cities $=$ (accessed on the $8^{\text {th }}$ December 2019).

[20] Airqo. 2020. Know Your Air. From:https://www.airqo.net/ (accessed on the $13^{\text {th }}$ of Dec. 2020).

[21] Akumu, J. 2014. Improving Air Quality in African Cities. From:

https://wedocs.unep.org/bitstream/handle/20.500.11 822/16824/Overview_AirPollution_Africa.pdf?sequ ence $=1$ (accessed on the $29^{\text {th }}$ Nov. 2019).

[22] Alam M.J.B., Rahman M.H and Jaigirdar M.A. 1999. Ambient Air Quality At Roadside In Dhaka City. From:

http://www.envirobiotechjournals.com/article_abstra ct.php?aid $=3365 \&$ iid $=123 \&$ jid $=4$ (accessed on $20^{\text {th }}$ Jan 2021).

[23]Ai, Z.T, Mak, C.M and Lee.H,C. 2016. Roadside air quality and implications for control measures: A case study of Hong Kong. From: https://www.sciencedirect.com/science/article/abs/pi i/S1352231016303168.

[24] Worldweatheronline. 2020. Mukono weather. From:

https://www.worldweatheronline.com/mukonoweather-averages/mukono/ug.aspx (accessed on the 5th of March 2020).

[25] South Coast AQMD, 2019.Air Quality Sensor Performance Evaluation Centre.Summary Tables \& Reports. From: http://www.aqmd.gov/aqspec/evaluations/summary-pm (accessed on the 13th of Feb.2020).23rd of Nov. 2019).

[26]Elite Weather Systems NZ.2020. Purpleair Air Quality Sensor PA-II-SD. From 
https://www.elite-weather-systems-

nz.com/products/purpleair-air-quality-sensor-pa-ii (accessed on the $13^{\text {th }}$ Feb.2020).

[27] U.S. Embassy in Uganda.(2020). Air Quality Monitoring at U.S. Embassy Kampala. Form: https://ug.usembassy.gov/embassy/kampala/airquality-monitoring-at-u-s-embassy-kampala/ (accessed on the $8^{\text {th }}$ Dec. 2019).

[28]EPA. 2017. Quality Assurance Handbook for Air Pollution Measurement Systems Volume II Ambient AirQuality Monitoring Program From:https://www3.epa.gov/ttnamti1/files/ambient/p $\mathrm{m} 25 / \mathrm{qa} /$ Final\%20Handbook\%20Document\%201_17 .pdf(accessed on the 19th of Feb 2020).

[29]RC.n.d. Assessment on siting criteria, classification and representativeness of air quality monitoring stations. From: https://ec.europa.eu/environment/air/pdf/SCREAM \%20final.pdf (accessed 12 ${ }^{\text {th }}$ May 2019).

[30]UNEP. 2017. Uganda Air Quality Policies. From:

https://wedocs.unep.org/bitstream/handle/20.500.11 822/17133/Uganda.pdf?sequence=1\&isAllowed=y (accessed on the $5^{\text {th }}$ of Dec. 2019).

[31] The World Bank Data. 2020. Death rate, crude (per 1,000 people) - Uganda. From: https://data.worldbank.org/indicator/SP.DYN.CDRT .IN?locations=UG (accessed $30^{\text {th }}$ November, 2020). [32] enHealth. 2012. Environmental Health Risk Assessment. Guidelnes for assessing human health risks from environmental hazards. From: https://www1.health.gov.au/internet/main/publishing .nsf/content/A12B57E41EC9F326CA257BF0001F9 E7D/\$File/Environmental-health-Risk-

Assessment.pdf.

[33] Liu.S.V, Chen Fu-lin and Xue J. 2019. A metaanalysis of selected near-road air pollutants based on concentration decay rates. Heliyon, Vol. 5, Issue 8 DOI: https://doi.org/10.1016/j.heliyon.2019.e02236. [34]NEMA. 2019. WORLD ENVIRONMENT DAY. 5TH JUNE 2019 CELEBRATED. Theme: "Fight Air Pollution to Protect Human Health and Environment"

https://nema.go.ug/sites/all/themes/nema/docs/Jun e\%202019_NEMA\%20Newsletter\%20(1).pdf

(Accessed on the $4^{\text {th }}$ Dec 2019).
[35]Penkała M, OgrodnikP andRogula-Kozłowska W. 2018. Particulate Matter from the Road Surface Abrasion as a Problem of Non-Exhaust Emission Control. From file://C:/Users/ICMI\%20UCU/Downloads/enviro nments-05-00009.pdf.

[36] WHO. 2019c. Ambient air pollution: Health impacts.

From:

https://www.who.int/airpollution/ambient/health-

impacts/en/ (accessed on the $5^{\text {th }}$ Dec. 2019).

[37]Mohammadyan M, Keyvani S, Bahrami A, Yetilmezsoy K, Heibati B, Krystal J and Pollitt G. 2019. Assessment of indoor air pollution exposure in urban hospital microenvironments. From: https://core.ac.uk/download/pdf/199660135.pdf (accessed $17^{\text {th }}$ December, 2020).

[38]EPA. 2015.Near Roadway Air Pollution and Health: Frequently Asked Questions. From: https://www.epa.gov/sites/production/files/2015-

11/documents/420f14044_0.pdf.

[39] National Weather Service. 2020.Beaufort Scale. From: https://www.weather.gov/pqr/beaufort.

[40]Ren M, Fang X, Li M, SSun S, Pei L, Xu Q, Ye X, Cao Y, "Concentration-Response Relationship between PM2.5 and Daily Respiratory Deaths in China: A Systematic Review and Metaregression Analysis of Time-Series Studies", BioMed Research International, vol. 2017, Article ID 5806185, 15 pages, 2017. https://doi.org/10.1155/2017/5806185. [41]EPA. 2015b. Best Practices for Reducing NearRoad Pollution Exposure at Schools. From: https://www.epa.gov/sites/production/files/201510/documents/ochp_2015_near_road_pollution_boo klet_v16_508.pdf.

[42]EPA.2020. History of Reducing Air Pollution from Transportation in the United States. From: https://www.epa.gov/transportation-air-pollutionand-climate-change/accomplishments-and-successair-pollution-

transportation\#: :text=New\%20passenger\%20vehicl es $\% 20$ are $\% 2098$,pollutants $\% 20$ compared $\% 20$ to $\% 20$ the $\% 201960$ s.\&text $=$ U.S. $\% 20$ cities $\% 20$ have $\% 20 \mathrm{mu}$ ch\%20improved,sparked\%20technology\%20innovat ion $\% 20$ from $\% 20$ industry. 